\title{
Strike three for GLI3
}

Leslie Biesecker

National Institutes of Health, National Human Genome Research Institute, Laboratory of Genetic Disease Research, Bethesda, Maryland, USA. e-mail: leslieb@helix.nih.gov

Nature Genet. 17, 259-260

Due to an error on our part, the legend to Fig. 1 (below) was not printed in its entirety. We regret this error.

Fig. $1 \mathrm{GL/3}$ mutation and consequent effect (an hypothesis). Full-length GL/-3 consists of seven conserved domains, including the DNA-binding, zinc-finger and microtubular anchor domains. Beneath the amino-terminal end of the depicted protein are bars that represent proteins that are predicted to arise from truncating mutations in GCPS. PHS and PAP-A; the hatched portion of the bar indicates the known range in length of the predicted truncation products. These may act to repress or activate transcription. Phenotypic manifestations of the disorders include anterior or preaxial polydactyly (pre), posterior or postaxial polydactyly (post), central or insertional polydactyly (cen), syndactyly (syn), hypothalamic hamartoma (HH), hypertelorism (HT) and visceral anomalies (V). The colour of symbols and boxes in and indicate the proposed mechanism by which each phenotype is proposed to occur; Rep, repressor; Act, activator. Speckled boxes indicate variant features.

\section{errata}

\section{Heterozygote advantage for HLA class-II type in hepatitis B virus infection}

Mark R.Thursz' ${ }^{1}$, Howard C.Thomas' ${ }^{1}$ Brian M. Greenwood ${ }^{2}$ \& Adrian V.S. Hill ${ }^{3}$

'Hepatology Unit, Academic Department of Medicine, Imperial College School of Medicine at St. Mary's, London W2 $1 \mathrm{NY}$, UK. ${ }^{2}$ Medical Research Council Laboratories, P.O. Box 273, Fajara, The Gambia. ${ }^{3}$ The Wellcome Trust Centre for Human Genetics, University of Oxford, Windmill Road, Oxford OX3 7BN, UK. Correspondence should be addressed to M.R.T.

Nature Genet. 17, 10-11 (1997).

There was a typographical error in table 1 (printed below) under the category HLA-B. 113 heterozygotes were cleared of hepatitus B; not 13 as originally printed. The author regrets this error.

Table 1 The numbers of homozygotes and heterozygotes for HLA class-I and class-I loci in Gambians who had cleared HBV or were persistently infected with this virus

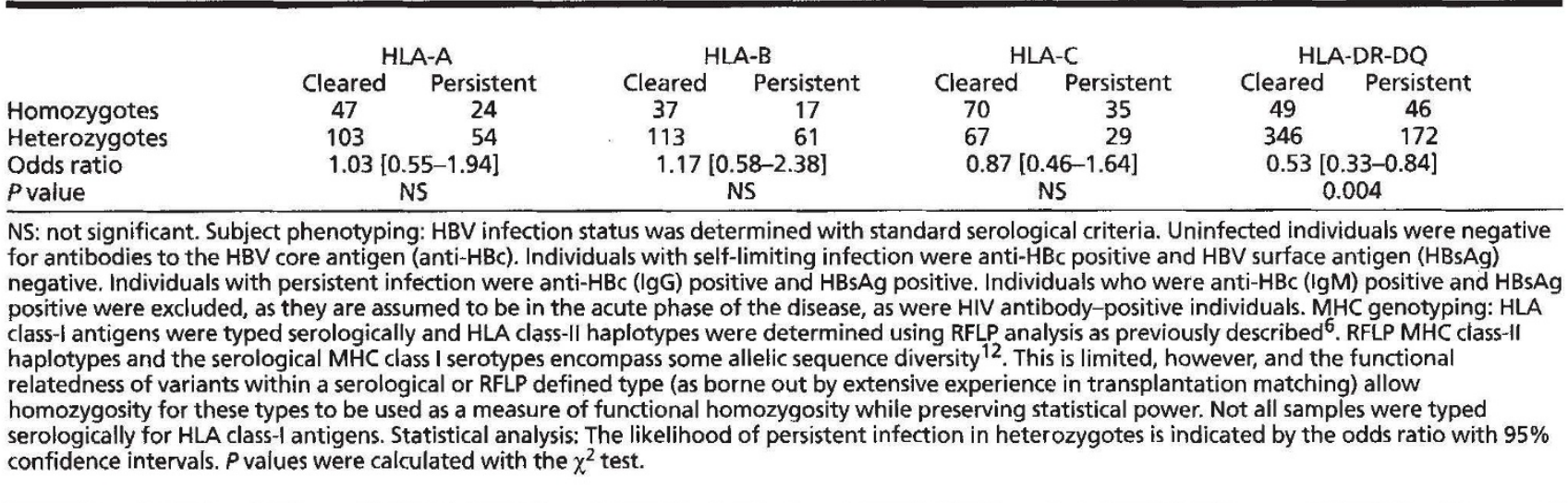

\section{Early diabetes and abnormal postnatal pancreatic islet development in mice lacking Glut-2}

Marie-Thérèse Guillam ${ }^{1}$, Edith Hümmler ${ }^{1}$, Elisabeth Schaerer ${ }^{1}$, Jih-l Yeh ${ }^{2}$, Morris J. Birnbaum ${ }^{3}$, Friedrich Beermann ${ }^{4}$, Andrea Schmidt $^{4}$, Nathalie Dériaz ${ }^{1} \&$ Bernard Thorens ${ }^{1}$

${ }^{1}$ Institute of Pharmacology and Toxicology, 27, rue du Bugnon, 1005 Lausanne, Switzerland. ${ }^{2}$ Department of Family Medicine, National Taiwan University Hospital, 7 Chung-Shan South Road, Taipei, Taiwan. ${ }^{3}$ Howard Hughes Medical Institute, University of Pennsylvania School of Medicine, Philadeiphia, Pennsylvania 19104-6148, USA. ${ }^{4}$ Swiss Institute for Experimental Research on Cancer, Ch. des Boveresses, 1066 Epalinges, Switzerland. Correspondence should be addressed to B.T. e-mail: Bernard.Thorens@ipharm.unil.ch

Nature Genet. 17, 327-330 (1997).

Dr. Jih-I Yeh's name was mistakenly listed as J.-Y. Wu when originally printed. The author regrets this error. 